\title{
Management of endocrine surgical disorders during COVID-19 pandemic: expert opinion for non-surgical options
}

\author{
Orhan Agcaoglu ${ }^{1} \cdot$ Atakan Sezer $^{2}$ (D) $\cdot$ Ozer Makay $^{3} \cdot$ Murat Faik Erdogan $^{4} \cdot$ Fahri Bayram $^{5} \cdot$ Sibel Guldiken $^{6}$. \\ Marco Raffaelli ${ }^{7}$. Yusuf Alper Sonmez ${ }^{8}$. Yong-Sang Lee ${ }^{9} \cdot$ Kyriakos Vamvakidis $^{10} \cdot$ Radu Mihai $^{11} \cdot$ Quan-Yang Duh $^{12}$. \\ Baris Akinci ${ }^{13} \cdot$ Faruk Alagol $^{14} \cdot$ Martin Almquist $^{15} \cdot$ Marcin Barczynski $^{16} \cdot$ Taner Bayraktaroglu $^{17}$. Eren Berber ${ }^{18}$. \\ Yusuf Bukey ${ }^{19}$. Guldeniz Karadeniz Cakmak ${ }^{20}$. Nuh Zafer Canturk ${ }^{21}$. Zeynep Canturk ${ }^{22}$ - Mehmet Celik ${ }^{6}$. \\ Ozlem Celik ${ }^{23}$ - Banu Ozturk Ceyhan ${ }^{24}$. Sergii Cherenko ${ }^{25}$. Thomas Clerici ${ }^{26}$. David Scott Coombes ${ }^{27}$. \\ Orhan Demircan ${ }^{28}$. Oguzhan Deyneli ${ }^{14}$. Gianlorenzo Dionigi ${ }^{29}$. Ali Ugur Emre ${ }^{20}$. Yesim Erbil ${ }^{24}$. Ali Ilker Filiz ${ }^{30}$. \\ Hulya llıksu Gozu ${ }^{31}$. Sibel Ozkan Gurdal ${ }^{32}$. Gunay Gurleyik ${ }^{33}$ - Mehmet Haciyanli ${ }^{34}$ - Abut Kebudi $^{30}$. \\ Seokmo Kim ${ }^{9}$ - Giannis Koutelidakis ${ }^{35}$. Bekir Kuru ${ }^{36}$. Meral Mert ${ }^{37}$. Guzide Gonca Oruk ${ }^{38}$ - Serdar Ozbas ${ }^{24}$. \\ Fausto Palazzo ${ }^{39}$. Rumen Pandev ${ }^{40}$. Phillip Riss ${ }^{41}$. Tevfik Sabuncu ${ }^{42}$. Ibrahim Sahin ${ }^{43}$. Gurhan Sakman ${ }^{44}$. \\ Fusun Saygili ${ }^{45}$. Yasemin Giles Senyurek ${ }^{46}$. Ilya Sleptsov ${ }^{47}$. Sam Van Slycke ${ }^{48}$. Serkan Teksoz ${ }^{19}$. Tarik Terzioglu $^{49}$. \\ Serdar Tezelman ${ }^{1} \cdot$ Fatih Tunca $^{46}$ - Mustafa Umit Ugurlu ${ }^{50} \cdot$ Mehmet Uludag $^{51}$ - Jesus Villar-del-Moral ${ }^{52}$. \\ Menno Vriens ${ }^{53}$. Dilek Yazici ${ }^{14}$
}

Received: 10 October 2020 / Accepted: 12 January 2021 / Published online: 11 April 2021

(c) Italian Society of Surgery (SIC) 2021

\begin{abstract}
Purpose The COVID-19 pandemic brought unprecedented conditions for overall health care systems by restricting resources for non-COVID-19 patients. As the burden of the disease escalates, routine elective surgeries are being cancelled. The aim of this paper was to provide a guideline for management of endocrine surgical disorders during a pandemic.

Methods We used Delphi method with a nine-scale Likert scale on two rounds of voting involving 64 experienced eminent surgeons and endocrinologists who had the necessary experience to provide insight on endocrine disorder management. All voting was done by email using a standard questionnaire.

Results Overall, 37 recommendations were voted on. In two rounds, all recommendations reached an agreement and were either endorsed or rejected. Endorsed statements include dietary change in primary hyperparathyroidism, Cinacalcet treatment in secondary hyperparathyroidism, alpha-blocker administration for pheochromocytoma, methimazole $\pm \beta$-blocker combination for Graves' disease, and follow-up for fine-needle aspiration results of thyroid nodules indicated as Bethesda 3-4 cytological results and papillary microcarcinoma.

Conclusion This survey summarizes expert opinion for the management of endocrine surgical conditions during unprecedented times when access to surgical treatment is severely disrupted. The statements are not applicable in circumstances in which surgical treatment is possible.
\end{abstract}

Keywords Consensus · Endocrine disease $\cdot$ Expert opinion $\cdot$ Pandemic $\cdot$ Qualtrics $\cdot$ Survey

\section{Introduction}

Humanity is experiencing an extraordinary period in which coronavirus disease 2019 (COVID-19) has become one of the biggest health issues of the current century. Due to

Atakan Sezer

atakansezer@hotmail.com

Extended author information available on the last page of the article this extraordinary crisis, health systems in many countries have come to a point in which they can deal only with the COVID-19 pandemic, causing many routine surgical procedures to be postponed [1, 2]. Operation room schedules for cancer patients are becoming more contracted as the demand for specific care of COVID-19 patients is increasing in most hospitals. With the escalation of the epidemic, surgical wards are also progressively being reserved for COVID-19 patients. Therefore, hospital beds allocated for COVID-19 
patients further decrease other patients' chances for receiving timely surgery [3-5].

Endocrine surgical procedures are amongst the most common elective operations in clinical practice. Management of endocrine patients who cannot be treated surgically due to the current circumstances is also an ongoing matter of uncertainty. Therefore, alternative treatment algorithms may be considered valid options. However, there is no evidencebased medical data regarding the management of endocrine disorders in case of an outbreak, such as COVID-19.

The pandemic we are going through these days may repeat itself in coming years. Therefore, as specialists on endocrine disorders, we must be ready for the next extraordinary situation. Hence, it is necessary to build a consensus by a group of experts on how to manage endocrine disorders during times like the COVID-19 pandemic.

The purpose of this survey is to clarify the treatment algorithms of basic endocrine scenarios, which would normally require surgery but have to be postponed due to a situation, such as the pandemic, in the perspective of experts in the field.

\section{Materials and methods}

An expert opinion development procedure was designed using the Delphi method. At first, an open-ended, unstructured, pilot survey was developed and distributed to the multidisciplinary research group including a total of eight endocrinologists and endocrine surgeons. After the verification of this core questionnaire and based on the responses received, a multiple-choice structured survey was designed.

The inclusion criteria of experts were considered, having at least 6 years of general endocrine practice experience, dealing with endocrine patients for at least $50 \%$ of his/her daily clinic time, working at a tertiary reference hospital with comprehensive endocrine disorders treatment facilities for a minimum of 5 years, and attending regular multidisciplinary tumor boards every week for a minimum of 5 years. The authors approached prominent members of the European Society of Endocrine Surgeons and Turkish Association of Endocrine Surgery, recognized by their peers through the regular activities of these societies. Every attempt was made to obtain a wide coverage of different countries.

The consensus design consists of recommendations (other than surgery) for different case scenarios including primary and secondary hyperparathyroidism, Graves' disease, pheochromocytoma, adrenal cancer, and thyroid fine-needle aspiration cytology (FNAC) results which normally require surgery based on current guidelines. Experts were requested to vote on the alternatives considered when surgical treatment is not a suitable option for a temporary period. In all the cases presented, the patients were assumed to be otherwise healthy, COVID-19-free, and without any co-morbidity limiting surgery.

All correspondence with the panelists was done by e-mail. The survey consisted of 37 questions and was administered online using Qualtrics ${ }^{\circledR}$ software link. Questions included demographics and treatment algorithms of most frequent endocrine disorders, which require surgery. A Likert scale from 1 (strongly disagree) to 9 (strongly agree) was used for voting on each question. The results for each recommendation were grouped into three categories including 1-3 (disagree), 4-6 (abstain) and 7-9 (agree).

For any decision to be made, voting on recommendation statements needed to pass through 2 steps. First, quorum needs to be attained and second, any of the endorsement or rejection thresholds of $75 \%$ should be met at each round. If the voting on a recommendation did not attain the quorum or pass the threshold for any decision, the situation was regarded as "consensus was not reached". If quorum is attained but votes did not cross the thresholds, the question was included in a second round of voting. During the second round, the same requirements for each decision were sought. If the thresholds were attained at any round, the consensus procedure was regarded as complete for that certain recommendation. On the other hand, if a decision had not been reached for a recommendation at the end of second round, the result for that recommendation was regarded as "consensus not reached-inconclusive".

No statistical analysis was used. Results of each voting minimum at one round were given as descriptive variable $(n: \%)$.

\section{Results}

A total of 37 consensus statements on different treatment algorithms were drafted and sent to the experts for voting (Table 1).

Sixty-seven physicians were nominated as experts according to eligibility criteria. From them, 45 were endocrine surgeons and 22 endocrinologists. The participating countries included Austria, Belgium, Bulgaria, Greece, Italy, the Netherlands, Poland, Russia, South Korea, Spain, Sweden, Switzerland, Turkey, Ukraine, the United Kingdom and USA.

The first round of consensus voting was completed on May 20, 2020. At this round, 64 (94\%) panelists responded with their vote; therefore, quorum was attained. Forty-one of them were endocrine surgeons and 23 were endocrinologists. Three statements were endorsed and 28 were rejected. Six recommendations in which consensus was not reached (recommendations no: 1, 6, 10, 24, 27 and 29) were sent to panelists for re-voting on the second round (attendance, n: 56, 83\%) completed on May 30, 2020. All six recommendations 
Table 1 Condition In patients who are physically fit and without any co-morbidity, under exceptional circumstances like COVID-19 outbreak in which routine surgical management is suspended for a temporary period of time

\section{Scenarios}

Patients who are diagnosed with symptomatic/asymptomatic primary hyperparathyroidism and candidate for surgery:

1. These patients should be treated with only dietary changes (low calcium intake + hydration) for 3 months

2. These patients should be treated with only Bisphosphanates for 3 months

3. These patients should be treated with only Calcitonin for 1 month

4. These patients should be treated with only Cinecalcet for 3 months

Comment:

Patients who are diagnosed with secondary hyperparathyroidism due to chronic renal insufficiency and candidate for surgery:

5. These patients should be treated with only dietary changes (low phosphorus intake + controlled hydration) for 3 months

6. These patients should be treated with only Cinecalcet for 3 months

7. These patients should be treated with only Calcitonin for 1 month

8. These patients should be treated with only Sevelamer for 3 months

9. These patients should be treated with only Dialysis for 3 months

Comment:

Patients who are diagnosed with pheochromacytoma (normotensive presentation) and candidate for surgery:

10. These patients should be treated with only $\alpha$-blocker for 3 months

11. These patients should be treated with combined $\alpha$ and $\beta$-blockers for 3 months

12. These patients should be treated with only metyrosine for 3 months

13. These patients should be treated with combined metyrosine and $\alpha$-blockers for 3 months

Comment:

Patients who are radiologically pre-diagnosed with adrenocortical carcinoma and candidate for surgery:

14. These patients should be treated with only radiotherapy

15. These patients should be treated with only chemotherapy

16. These patients should be followed-up with active surveillance principles

Comment:

Patients previously diagnosed with Graves' disease who are candidate for surgery:

17. These patients should be treated with only radioactive iodine treatment

18. These patients should be treated with only low iodine dietary change for 3 months

19. These patients should be treated with propylthiouracil $\pm \beta$-blocker for 3 months

20 . These patients should be treated with methimazole $\pm \beta$-blocker for 3 months

Comment:

Patients who underwent fine needle aspiration cytology (FNAC) for thyroid nodule and candidate for surgery:

Bethesda-3

21. Patients with FNAC result of two times of atypia or follicular lesion of undetermined significance (Bethesda-3) should be postponed for 3-6 months

22. Patients with FNAC result of two times of atypia or follicular lesion of undetermined significance (Bethesda-3) should be treated with minimally invasive ablation techniques including laser, microwave or radiofrequency ablation

23. Patients with FNAC result of two times of atypia or follicular lesion of undetermined significance (Bethesda-3) should be followed-up with active surveillance principles until the end of the pandemic

Comment:

Bethesda-4

24. Patients with FNAC result of Hürthle cell neoplasia or follicular neoplasia (Bethesda-4) should be postponed for 3-6 months

25. Patients with FNAC result of Hürthle cell neoplasia or follicular neoplasia (Bethesda-4) should be treated with minimally invasive ablation techniques including laser, microwave or radiofrequency ablation

26. Patients with FNAC result of Hürthle cell neoplasia or follicular neoplasia (Bethesda-4) should be followed-up with active surveillance principles until the end of the pandemic

Comment: 
Table 1 (continued)

Papillary microcarcinoma

27. Patients with FNAC result of papillary microcarcinoma (single nodule) should be postponed for 3-6 months

28. Patients with FNAC result of papillary microcarcinoma (single nodule) should be treated with minimally invasive ablation techniques including laser, microwave or radiofrequency ablation

29. Patients with FNAC result of papillary microcarcinoma (single nodule) should be followed-up with active surveillance principles until the end of the pandemic

Comment:

\section{Papillary carcinoma}

30. Patients with FNAC result of papillary carcinoma (without pathological lymph nodes in the neck) should be postponed for 3-6 months

31. Patients with FNAC result of papillary carcinoma (without pathological lymph nodes in the neck) should be treated with minimally invasive ablation techniques including laser, microwave or radiofrequency ablation

32. Patients with FNAC result of papillary carcinoma (with pathological lymph nodes at central neck) should be postponed for 3-6 months 33. Patients with FNAC result of papillary carcinoma (with pathological lymph nodes at lateral neck) should be postponed for 3-6 months Comment:

\section{Medullary carcinoma}

34. Patients with FNAC result of medullary carcinoma (without pathological lymph nodes in the neck) should be postponed for 3-6 months

35. Patients with FNAC result of medullary carcinoma (without pathological lymph nodes in the neck) should be treated with minimally invasive ablation techniques including laser, microwave or radiofrequency ablation

36. Patients with FNAC result of medullary carcinoma (with pathological lymph nodes at central neck) should be postponed for 3-6 months

37. Patients with FNAC result of medullary carcinoma (with pathological lymph nodes at lateral neck) should be postponed for 3-6 months

Comment:

All questions below were evaluated using a 9-scale Likert scale

1 to 9: Strongly Disagree to Strongly agree

on the second round were endorsed by the panel. Therefore, nine recommendations were endorsed and 28 were rejected overall. There were no recommendations left without a consensus (Table 2).

All recommendations were based on the assumption that necessary surgery cannot be carried out in endocrine patients under the COVID-19 pandemic conditions. The panel members endorsed only dietary changes (low calcium intake + hydration) for 3 months for patients who are diagnosed with symptomatic/asymptomatic primary hyperparathyroidism and are candidate for surgery. Regarding patients who are diagnosed with secondary hyperparathyroidism due to chronic renal insufficiency and are candidate for surgery, experts endorsed only cinacalcet treatment for 3 months. Related to Graves' disease, experts endorsed methimazole $\pm \beta$-blockers.

For adrenal disorders, while a majority of experts rejected any treatments other than surgery in patients with adrenal cancer, most of them endorsed only $\alpha$-blocker treatment in patients with pheochromocytoma.

Regarding scenarios after fine-needle aspiration cytology, while panelists endorsed postponing elective operations at least 3-6 months for nodules with Bethesda 3-4 cytologic results and papillary microcarcinomas without pathological lymph node involvement, they rejected all other options other than surgery in patients with a cancer diagnosis (papillary or medullary) or pathological lymph node involvement at the central or lateral neck compartment.

\section{Discussion}

The coronavirus disease 2019 named COVID-19 was first reported in Wuhan, China, then declared a pandemic by the World Health Organization. In a very short period, the pandemic turned into a worldwide crisis and demanded a major reform to the entire world healthcare system. Although COVID-19 patients received their crucial treatments, required to keep them in stable condition, other disorders which are not associated with COVID-19 that also require critical managements and were forced into mandatory deferral until the end of pandemic [1].

Endocrine disorders which need surgery in normal daily practice were among the leading group of patients who were delayed due to the pandemic. These patients included not only cancer patients, but also benign conditions, such as pheochromocytoma or Graves' disease, which can be life-threatening with prolonged surgical delays. Regarding the determination of patients who need urgent operations or those that can be safely deferred, many groups from other specialties including hepatobiliary, colorectal, and visceral surgeries reported guidelines or expert opinions [4-7]. However, for endocrine disorders, there is still scant 
Table 2 Condition: In patients who are physically fit and without any co-morbidity, under exceptional circumstances like COVID-19 outbreak in which routine surgical management is suspended for a temporary period of time

\begin{tabular}{|c|c|c|c|c|}
\hline Recommendation & Voting col & unts & & Result \\
\hline $\begin{array}{l}\text { Patients who are diagnosed with symptomatic/asymptomatic primary hyperparathyroidism and can- } \\
\text { didate for surgery: }\end{array}$ & Disagree & Abstain & Agree & \\
\hline $\begin{array}{l}\text { 1. These patients should be treated with only dietary changes (low calcium intake }+ \text { hydration) for } \\
3 \text { months }\end{array}$ & $10 \%$ & $14 \%$ & $75 \%$ & Endorsed \\
\hline 2. These patients should be treated with only Bisphosphonates for 3 months & $53 \%$ & $23 \%$ & $24 \%$ & Rejected \\
\hline 3. These patients should be treated with only Calcitonin for 1 month & $86 \%$ & $10 \%$ & $4 \%$ & Rejected \\
\hline 4. These patients should be treated with only Cinacalcet for 3 months & $34 \%$ & $29 \%$ & $37 \%$ & Rejected \\
\hline
\end{tabular}

\section{Patients who are diagnosed with secondary hyperparathyroidism due to chronic renal insufficiency} and candidate for surgery:

5. These patients should be treated with only dietary changes (low phosphorus intake + controlled hydration) for 3 months

6. These patients should be treated with only Cinacalcet for 3 months

7. These patients should be treated with only Calcitonin for one month

8. These patients should be treated with only Sevelamer for 3 months

9. These patients should be treated with only Dialysis for 3 months

Patients who are diagnosed with pheochromocytoma (normotensive presentation) and candidate for surgery:

10. These patients should be treated with only $\alpha$-blocker for 3 months

11. These patients should be treated with combined $\alpha$ and $\beta$-blockers for 3 months

12. These patients should be treated with only metyrosine for 3 months

13. These patients should be treated with combined metyrosine and $\alpha$-blockers for 3 months

Patients who are radiologically pre-diagnosed with adrenocortical carcinoma and candidate for surgery:

14. These patients should be treated with only radiotherapy

15. These patients should be treated with only chemotherapy

16. These patients should be followed-up with active surveillance principles

Patients previously diagnosed with Graves' disease who are candidate for surgery:

17. These patients should be treated with only radioactive iodine treatment

18. These patients should be treated with only low iodine dietary change for 3 months

19. These patients should be treated with propylthiouracil $\pm \beta$-blocker for 3 months

20. These patients should be treated with methimazole $\pm \beta$-blocker for 3 months

Patients who underwent fine needle aspiration cytology (FNAC) for thyroid nodule and candidate for surgery:

21. Patients with FNAC result of two times of atypia or follicular lesion of undetermined significance (Bethesda-3) should be postponed for 3-6 months

22. Patients with FNAC result of two times of atypia or follicular lesion of undetermined significance (Bethesda-3) should be treated with minimally invasive ablation techniques including laser, microwave or radiofrequency ablation

23. Patients with FNAC result of two times of atypia or follicular lesion of undetermined significance (Bethesda-3) should be followed-up with active surveillance principles until the end of the pandemic

24. Patients with FNAC result of Hürthle cell neoplasia or follicular neoplasia (Bethesda-4) should be postponed for 3-6 months

25. Patients with FNAC result of Hürthle cell neoplasia or follicular neoplasia (Bethesda-4) should be treated with minimally invasive ablation techniques including laser, microwave or radiofrequency ablation

26. Patients with FNAC result of Hürthle cell neoplasia or follicular neoplasia (Bethesda-4) should be followed-up with active surveillance principles until the end of the pandemic

27. Patients with FNAC result of papillary microcarcinoma (single nodule) should be postponed for 3-6 months

28. Patients with FNAC result of papillary microcarcinoma (single nodule) should be treated with mini- $88 \%$ mally invasive ablation techniques including laser, microwave or radiofrequency ablation

Disagree Abstain Agree

$\begin{array}{llll}25 \% & 30 \% & 45 \% & \text { Rejected } \\ 7 \% & 8 \% & 85 \% & \text { Endorsed } \\ 78 \% & 13 \% & 9 \% & \text { Rejected } \\ 34 \% & 42 \% & 24 \% & \text { Rejected } \\ 47 \% & 76 \% & 29 \% & \text { Rejected }\end{array}$

Disagree Abstain Agree

$\begin{array}{llll}15 \% & 10 \% & 75 \% & \text { Endorsed } \\ 25 \% & 30 \% & 45 \% & \text { Rejected } \\ 70 \% & 24 \% & 6 \% & \text { Rejected } \\ 58 \% & 31 \% & 11 \% & \text { Rejected }\end{array}$

Disagree Abstain Agree

$\begin{array}{llll}83 \% & 16 \% & 3 \% & \text { Rejected } \\ 68 \% & 18 \% & 14 \% & \text { Rejected } \\ 80 \% & 17 \% & 3 \% & \text { Rejected } \\ \text { Disagree } & \text { Abstain } & \text { Agree } & \\ 50 \% & 24 \% & 26 \% & \text { Rejected } \\ 65 \% & 21 \% & 14 \% & \text { Rejected } \\ 34 \% & 24 \% & 42 \% & \text { Rejected } \\ 6 \% & 11 \% & 83 \% & \text { Endorsed }\end{array}$

Disagree Abstain Agree

\begin{tabular}{llll}
$6 \%$ & $14 \%$ & $80 \%$ & Endorsed \\
$86 \%$ & $10 \%$ & $4 \%$ & Rejected \\
& & & \\
$9 \%$ & $13 \%$ & $78 \%$ & Endorsed \\
$3 \%$ & $12 \%$ & $85 \%$ & Endorsed \\
$84 \%$ & $12 \%$ & $4 \%$ & Rejected \\
& & & \\
$26 \%$ & $21 \%$ & $53 \%$ & Rejected \\
$3 \%$ & $6 \%$ & $91 \%$ & Endorsed \\
\hline $88 \%$ & $11 \%$ & $1 \%$ & Rejected
\end{tabular}


Table 2 (continued)

\begin{tabular}{|c|c|c|c|c|}
\hline \multirow{2}{*}{$\begin{array}{l}\text { Recommendation } \\
\text { 29. Patients with FNAC result of papillary microcarcinoma (single nodule) should be followed-up with } \\
\text { active surveillance principles until the end of the pandemic }\end{array}$} & \multicolumn{3}{|c|}{ Voting counts } & \multirow{2}{*}{ Result } \\
\hline & $7 \%$ & $16 \%$ & $77 \%$ & \\
\hline $\begin{array}{l}\text { 30. Patients with FNAC result of papillary carcinoma (without pathological lymph nodes in the neck) } \\
\text { should be postponed for 3-6 months }\end{array}$ & $26 \%$ & $64 \%$ & $38 \%$ & Rejected \\
\hline $\begin{array}{l}\text { 31. Patients with FNAC result of papillary carcinoma (without pathological lymph nodes in the neck) } \\
\text { should be treated with minimally invasive ablation techniques including laser, microwave or radiofre- } \\
\text { quency ablation }\end{array}$ & $93 \%$ & $7 \%$ & $0 \%$ & Rejected \\
\hline $\begin{array}{l}\text { 32. Patients with FNAC result of papillary carcinoma (with pathological lymph nodes at central neck) } \\
\text { should be postponed for 3-6 months }\end{array}$ & $76 \%$ & $16 \%$ & $8 \%$ & Rejected \\
\hline $\begin{array}{l}\text { 33. Patients with FNAC result of papillary carcinoma (with pathological lymph nodes at lateral neck) } \\
\text { should be postponed for 3-6 months }\end{array}$ & $84 \%$ & $12 \%$ & $4 \%$ & Rejected \\
\hline $\begin{array}{l}\text { 34. Patients with FNAC result of medullary carcinoma (without pathological lymph nodes in the neck) } \\
\text { should be postponed for 3-6 months }\end{array}$ & $92 \%$ & $4 \%$ & $4 \%$ & Rejected \\
\hline $\begin{array}{l}\text { 35. Patients with FNAC result of medullary carcinoma (without pathological lymph nodes in the neck) } \\
\text { should be treated with minimally invasive ablation techniques including laser, microwave or radiofre- } \\
\text { quency ablation }\end{array}$ & $96 \%$ & $3 \%$ & $1 \%$ & Rejected \\
\hline $\begin{array}{l}\text { 36. Patients with FNAC result of medullary carcinoma (with pathological lymph nodes at central neck) } \\
\text { should be postponed for 3-6 months }\end{array}$ & $91 \%$ & $3 \%$ & $6 \%$ & Rejected \\
\hline $\begin{array}{l}\text { 37. Patients with FNAC result of medullary carcinoma (with pathological lymph nodes at lateral neck) } \\
\text { should be postponed for } 3-6 \text { months }\end{array}$ & $94 \%$ & $0 \%$ & $6 \%$ & Rejected \\
\hline
\end{tabular}

and limited data in the literature [8]. Thus, there is no national or international case-based expert consensus or guidelines for endocrine disorders outlining alternative procedures for the conventional surgical algorithms. We believe that situations, such as this pandemic, may reoccur, and we should always be ready to manage these disorders with medical or alternative treatments in which elective surgeries are mandatorily postponed due to high risk.

The current consensus aims to methodize a guideline for endocrine specialists for practical management during outbreaks, such as COVID-19, applying a consensus development procedure with the Delphi method. With this methodology, we discussed featured endocrine disorders including primary and secondary hyperparathyroidism, pheochromocytoma, adrenocortical carcinoma, Graves' disease and the most frequent FNAC results.

\section{Primary hyperparathyroidism}

Even though patients with primary hyperparathyroidism (PHPT) are generally diagnosed incidentally as asymptomatic patients, many have symptomatic disease that can affect multiple systems including renal, skeletal and gastrointestinal $[9,10]$. Today, surgery remains the gold standard treatment for PHPT. The indications for surgery include all symptomatic patients, and asymptomatic cases with subclinical evidence of increased risk for organ failure [11].

According to the recent surgical guidelines, parathyroidectomy indications include elevated serum calcium levels ( $\geq 1 \mathrm{mg} / \mathrm{dl}$ above the normal upper limit), osteoporosis
(T-score $\leq-2.5 \mathrm{SD}$ ) or evidence of vertebral fractures on diagnostic work-up, decreased eGFR ( $<60 \mathrm{ml} / \mathrm{min}$ ), hypercalciuria ( $>400 \mathrm{mg} /$ day), nephrolithiasis or nephrocalcinosis on imaging studies, and age $<50$ years $[11,12]$. However, when the patients do not meet these indications, have substantial comorbidities or are in a pandemic situation in which elective surgeries cannot be performed, follow-up without an operation can also be an option [10].

To date, ideal medical treatment for non-operated patients may include hormones (estrogen), bisphosphonates or calcimimetics. However, no single medication can address all targets and replace surgery. Among these medications, cinacalcet (calcimimetic) successfully decreases serum calcium levels and has already been reported as one of the key drugs for treating PHPT, especially for those patients who are not candidates for surgery [13]. In the expert opinion, panelists endorsed dietary changes for the first line of treatment. However, it has also been noted that, for patients with calcium levels above $13 \mathrm{mg} / \mathrm{dl}$ or those with hypercalcemic crisis, the best option is surgery due to the increased risk of mortality $[14,15]$. In these cases, cinacalcet may also have a significant role as medical treatment [16].

\section{Secondary hyperparathyroidism}

According to the guidelines, surgery is indicated for patients who are refractory to medical therapy [17, 18]. Moreover, surgical treatment is generally not recommended during a pandemic due to the elevated risk of infection in patients who underwent dialysis [19]. Regarding medical treatment, 
calcimimetics and vitamin D agents have become the mainstay of medical treatment for secondary hyperparathyroidism [20]. Other pharmacological options, such as phosphorus binders, calcium-containing salts or calcium-free binders, such as sevelamer (effective if the phosphorus level is above $4 \mathrm{mg} / \mathrm{dl}$ ), have limited use as therapy in secondary hyperparathyroidism and their effects on survival are uncertain $[21,22]$.

Recent clinical trials confirmed the safety and feasibility of cinacalcet as a standard therapy in combination with active vitamin $\mathrm{D}$ agents and phosphorus binders [23]. However, it should be noted that, cinacalcet may lead to hypocalcemia and hypercalciuria which may not be suitable for a patient with chronic renal failure. Thus, the right medical algorithm in a pandemic period includes dietary changes, cinacalcet, sevelamer, and dialysis if indicated. The current panel endorsed cinacalcet for the treatment of secondary hyperparathyroidism in the pandemic period.

\section{Pheochromocytoma}

Medical treatment options for pheochromocytoma include alpha-blockers, a combination of alpha and beta-blockers, beta-blockers, calcium channel blockers and metyrosine. Thus, clinical trials that include randomized, prospective, and controlled studies comparing different pharmacological agents for the treatment of pheochromocytoma are lacking.

In the current study, experts endorsed extended alpha blockage treatment as in a prolonged perioperative period in patients with a pheochromocytoma diagnosis, if effective in controlling clinical symptoms of the disease and in the absence of radiological features of malignancy. However, due to its increased risk of mortality, this potentially lifethreatening disorder can require urgent surgical treatment [24].

\section{Adrenocortical cancer}

Metastatic or advanced tumors are directly associated with poor prognosis and do not have an effective therapy [25]. Prognosis is mostly related to the stage of the tumor and operability criteria. To date, $\mathrm{R} 0$ resection of the tumor with adjuvant Mitotane treatment results with the highest survival pattern $[25,26]$. However, there are scant data to support a targeted therapy in patients with advanced ACC beyond ongoing clinical trials and debates regarding the use of chemotherapeutics or radiotherapy for neoadjuvant therapy $[27,28]$. Due to the significant value of pathological factors including the stage of the disease and tumor-free resection margins for prognosis, even in a pandemic situation, ACC requires urgent surgical treatment (within 30 days) [29]. As mentioned in the literature, the panelists reject all alternative treatment modalities and endorsed surgery for ACC if the patient is operable [29].

\section{Graves' disease}

The treatment modality of Graves' disease (GD) includes anti-thyroid drugs (ATD), radioactive iodine (RAI) treatment or a thyroidectomy [30]. Among these treatments, ATD are indicated as first-line treatments of GD, mostly for temporary management before RAI treatment or surgery $[30,31]$.

Panelists endorsed a methimazole and beta-blocker combination for initial therapy during the pandemic and rejected dietary changes and RAI treatment. Only challenging cases including patients with hematological problems, such as neutropenia/pancytopenia, significant comorbidities in which ATDs are contraindicated, refractory cases to medical treatment, rapidly worsening of ophthalmopathy in spite of medical treatment, or asthmatic patients unable to use beta-blockers may require urgent surgery.

\section{Thyroid cancer}

Differentiated cancers usually have an excellent prognosis. However, in aggressive subtypes, such as tall cell variants, tumors larger than $4 \mathrm{~cm}$, or those with pathological lymph node involvement or signs of local invasion like nerve palsy, surgery must be considered the first line of treatment even during COVID-19 pandemic [32, 33].

Regarding papillary microcarcinomas (PMC), most patients are diagnosed with intrathyroidal "low and intermediate risk" cancers with an indolent course and excellent prognosis. The American Thyroid Association (ATA) guidelines also endorsed an active surveillance approach as a low-risk PMC management alternative to immediate surgery [32]. Although the active follow-up approach is being increasingly approved worldwide, the available data on the outcome of active surveillance of PMC are currently only from the East, and additional data should be obtained in several different populations [34]. Of note, in some settings, it could be difficult to ensure adequate follow-up during the acute phase of pandemic, due to restriction of outpatient consultation. In addition, there are also some alternative therapeutic options including radiofrequency ablation (RFA) and percutaneous ethanol injection therapy (PEIT) $[35,36]$. However, using these minimally invasive techniques may result in destruction of the final histopathological specimen. Our panelists endorsed the deferral of papillary microcarcinomas in the pandemic period and rejected alternative minimally invasive treatments, such as PEIT or RFA.

Finally, regarding medullary cancer patients, due to its aggressive behavior, current guidelines recommend at least 
total thyroidectomy and central neck dissection. To prevent a possible extension to the lateral neck lymph nodes, we believe that urgent surgery is the best option. Parallel to this idea, the panelists rejected follow-up of medullary cancers even in a pandemic scenario [37].

Since there is no evidence for what to do in these clinical situations, all consensus statements were provided for clinical conditions in which surgical treatment was not possible. Expert opinions were gathered to obtain a consensus. Thus, possible limitations of the statement recommendations derived of three topics: the Delphi methodology, the disparity in clinical practice and consensuses, and the composition of the panel.

A group of consecutive questions in two rounds were sent to the experts of the panel to obtain the most factual opinion in a clinically ambiguous situation to shed light on an area with lack of high level of evidence. In practice, the methods are easy to answer and user friendly. On the other hand, low-grade precision of the statements and the difficulty of taking comments into account are some weaknesses Delphi method. The structure of grading with a 9-point Likert scale may be confusing to the panelists [38]. To identify the difference between grade 3 from 5, or 6 from 8 in clinical scenarios may not represent the real world. As the grading system directs the thresholds, some recommendations were rejected due to votes. Twenty-eight of the statements that did not reach enough agreement for recommendation met the rejection threshold at $25 \%$. Therefore, even in this example, rough results of voting can help guide clinicians with patient management in such scenarios.

On the other hand, clinical practice and the statements of the consensus may have disparities. In clinical practice, the management of endocrine disorders is established by evidence-based medicine, but for consensus statements made for outbreak circumstances like COVID-19 the evidence is inconclusive. Although the scenarios depicted in the survey pertain to strict conditions in which surgery is not considered a viable option, a majority of the recommendations surveyed by the panel did not reach a conclusion with a non-surgical option. Therefore, in these scenarios, rough voting results may help clinicians to decide what to do. Although our consensus results outline guidance for daily practice under these pandemic circumstances, the results do not depend on high-level evidence but rather on expert opinion and someway influenced also by local diffusion of the pandemic and different political decisions in different health systems. Therefore, the final decision on how to manage these patients is at the physicians' discretion. It is crucial that practical and rational solutions are found taking multidisciplinary tumor boards into account. Therefore, we believe that these consensus results can help clinicians dealing with endocrine patients under the restrictive and pressing conditions of the COVID-19 pandemic.
The results of this consensus should be regarded only in circumstances in which surgery is not feasible, otherwise it is indicated as standard procedure. Therefore, if it is possible to perform surgical procedures in patients within the clinical scenarios described, surgery should be the mainstay treatment. The consensus results should not be regarded under normal conditions.

Acknowledgements The first draft of the manuscript was written by the authors including Orhan Agcaoglu, Atakan Sezer, Ozer Makay, Murat Faik Erdogan, Fahri Bayram, Sibel Guldiken, Marco Raffaelli, Yusuf Alper Sonmez, Yong-Sang Lee, Kyriakos Vamvakidis, Radu Mihai, Quan-Yang Duh. All authors in the study commented on the manuscript. All authors read and approved the final manuscript.

Author contributions Conceptualization, Methodology, Design, Data collection, Formal analysis and investigation, Writing, and Supervision, Final approval: OA, AS, OM, MFE, FB, SG, MR, YAS, Y-SL, KV, RM, Q-YD. Methodology, Data collection, Review and editing; Final approval: BA, FA, MA, MB, TB, EB, YB, GKC, NZC, ZC, MC, OC, BOC, SC, TC, DSC, OD, OD, GD, AUE, YE, AIF, HIG, SOG, GG, MH, AK, SK, GK, BK, MM, GGO, SO, FP, RP, PR, TS, IS, GS, FS, YGS, IS, SVS, ST, TT, ST, FT, MUU, MU, JV-M, MV, DY.

Funding This study has IRB Approval from Trakya University.

\section{Compliance with ethical standards}

Conflict of interests The authors have no conflict of interest and nothing to disclose.

Research involving human participants and/or animals This article does not contain any studies with human participants or animals performed by any of the authors. The survey included in this article has been approved by the Trakya University Institutional Review Board.

Informed consent For this type of study, formal consent is not required.

\section{References}

1. Zarzaur BL, Stahl CC, Greenberg JA, Savage SA, Minter RM (2020) Blueprint for restructuring a department of surgery in concert with the health care system during a pandemic: The University of Wisconsin experience. JAMA Surg. 155(7):628-635

2. Ayyaz M, Butt UI, Umar M, Khan WH, Kashif MR, Hyidar Z (2020) Effect of COVID-19 on the working of a tertiary care hospital. J Coll Physicians Surg Pak 30(10):164-167

3. McBride KE, Brown KGM, Fisher OM, Steffens D, Yeo DA, Koh CE (2020) Impact of the COVID-19 pandemic on surgical services: early experiences at a nominated COVID-19 centre. ANZ J Surg 90:663-665

4. Besnier E, Tuech JJ, Schwarz L (2020) We asked the experts: Covid-19 outbreak: is there still a place for scheduled surgery? "Reflection from pathophysiological data." World J Surg 44:1695-1698

5. Al-Omar K, Bakkar S, Khasawneh L, Donatini G, Miccoli P (2020) Resuming elective surgery in the time of COVID-19: a safe and comprehensive strategy. Updates Surg 72(2):291-295

6. Tuech JJ, Gangloff A, Di Fiore F, Michel P, Brigand C, Slim K et al (2020) Strategy for the practice of digestive and oncological surgery during the COVID-19 epidemic. J Visc 157:7-12 
7. Iacobucci G (2020) COVID-19: all non-urgent elective surgery is suspended for at least 3 months in England. BMJ 368:m1106

8. Baud G, Brunaud L, Lifante JC, Tresallet C, Sebag F, Bizard JP et al (2020) Endocrine surgery during and after the COVID-19 epidemic: guidelines from AFCE. J Chir Visc 157:44-51

9. Cope O (1966) The study of hyperparathyroidism at the Massachusetts General Hospital. N Engl J Med 274:1174-1182

10. Silverberg SJ, Shane E, Jacobs TP, Siris E, Bilezikian JP (1999) A 10-year prospective study of primary hyperparathyroidism with or without parathyroid surgery. N Engl J Med 341:1249-1255

11. Bilezikian JP (2014) Guidelines for the management of asymptomatic primary hyperparathyroidism: summary statement from the Fourth International Workshop. J Clin Endocrinol Metab 99:3561-3569

12. Wilhelm SM (2016) The American Association of Endocrine Surgeons Guidelines for definitive management of primary hyperparathyroidism. JAMA Surg 151:959-968

13. Marcocci C, Bollerslev J, Khan AA, Shoback DM (2014) Medical management of primary hyperparathyroidism: proceedings of the fourth International Workshop on the Management of Asymptomatic Primary Hyperparathyroidism. J Clin Endocrinol Metab 99:3607-3618

14. Cannon J, Lew JI, Solorzano CC (2010) Parathyroidectomy for hypercalcemic crisis: 40 years' experience and long-term outcomes. Surgery 148:807-813

15. Roy R, Lee JA (2011) Calciphylaxis due to hyperparathyroidism. Endocr Pract 17:54-56

16. Peacock M, Bilezikian JP, Klassen PS, Guo MD, Turner SA, Shoback D (2005) Cinacalcet hydrochloride maintains long-term normocalcemia in patients with primary hyperparathyroidism. $\mathrm{J}$ Clin Endocrinol Metab 90:135-141

17. Block GA, Klassen PS, Lazarus JM, Ofsthun N, Lowrie EG, Chertow GM (2004) Mineral metabolism, mortality, and morbidity in maintenance hemodialysis. J Am Soc Nephrol 15:2208-2218

18. Schneider R, Slater EP, Karakas E, Bartsch DK, Schlosser K (2012) Initial parathyroid surgery in 606 patients with renal hyperparathyroidism. World J Surg 36:318-326

19. Ikizler TA, Kliger AS (2020) Minimising the risk of COVID-19 among patients on dialysis. Nat Rev Nephrol 16:311-313

20. Chertow GM, Block GA, Correa-Rotter R, Drüeke TB, Floege J, Goodman WG et al (2012) EVOLVE Trial Investigators: effect of cinacalcet on cardiovascular disease in patients undergoing dialysis. N Engl J Med 367:2482-2494

21. London GM, Guerin AP, Marchais SJ, Metivier F, Pannier B, Adda $\mathrm{H}$ (2003) Arterial media calcification in end-stage renal disease: Impact on all-cause and cardiovascular mortality. Nephrol Dial Transplant 18:1731-1740

22. Bleyer AJ, Burke SK, Dillon M, Garrett B, Kant KS, Lynch D et al (1999) A comparison of the calcium-free phosphate binder sevelamer hydrochloride with calcium acetate in the treatment of hyperphosphatemia in hemodialysis patients. Am J Kidney Dis 33:694-701

23. Drueke TB, Ritz E (2009) Treatment of secondary hyperparathyroidism in CKD patients with cinacalcet and/or vitamin $\mathrm{D}$ derivatives. Clin J Am Soc Nephrol 4:234-241
24. Lenders JW, Duh QY, Eisenhofer G, Roqueplo APG, Grebe SKG, Murad MH et al (2014) Pheochromocytoma and paraganglioma: an endocrine society clinical practice guideline. J Clin Endocrinol Metab 99:1915-1942

25. Else T, Kim AC, Sabolch A, Raymond VM, Kandathil A, Caoili EM et al (2014) Adrenocortical carcinoma. Endocr Rev 35:282-326

26. Fassnacht M, Libé R, Kroiss M, Allolio B (2011) Adrenocortical carcinoma: a clinician's update. Nat Rev Endocrinol 7:323-335

27. Berruti A, Terzolo M, Sperone P, Pia A, Casa SD, Gross DJ et al (2005) Etoposide, doxorubicin and cisplatin plus mitotane in the treatment of advanced adrenocortical carcinoma: a large prospective phase II trial. Endocr Relat Cancer 12:657-666

28. Khan TS, Imam H, Juhlin C, Skogseid B, Gröndal S, Tibblin S et al (2000) Streptozocin and o, p'DDD in the treatment of adrenocortical cancer patients: longterm survival in its adjuvant use. Ann Oncol 11:1281-1287

29. Gaujoux S, Mihai R (2017) European Society of Endocrine Surgeons (ESES) and European Network for the Study of Adrenal Tumours (ENSAT) recommendations for the surgical management of adrenocortical carcinoma. Br J Surg 104:358-376

30. Smith TJ, Hegedus L (2016) Graves' disease. N Engl J Med 375:1552-1565

31. Bartalena L (2013) Diagnosis and management of Graves disease: a global overview. Nat Rev Endocrinol 9:724-734

32. Haugen BR, Alexander EK, Bible KC, Doherty GM, Mandel SJ, Nikiforov YE et al (2016) 2015 American Thyroid Association management guidelines for adult patients with thyroid nodules and differentiated thyroid cancer: the American Thyroid Association Guidelines Task Force on thyroid nodules and differentiated thyroid cancer. Thyroid 26:1-133

33. Bakkar S, Al-Omar K, Aljarrah Q, Al-Dabbas M, Al-Dabbas N, Samara $S$ et al (2020) Impact of COVID-19 on thyroid cancer surgery and adjunct therapy. Updates Surg 72(3):867-869

34. Ito Y, Miyauchi A, Oda H (2018) Low-risk papillary microcarcinoma of the thyroid: a review of active surveillance trials. Eur J Surg Oncol 44:307-315

35. Lim CY, Yun JS, Lee J, Nam KH, Chung WY, Park CS (2007) Percutaneous ethanol injection therapy for locally recurrent papillary thyroid carcinoma. Thyroid 17:347-350

36. Dupuy DE, Monchik JM, Decrea C, Pisharodi L (2001) Radiofrequency ablation of regional recurrence from well-differentiated thyroid malignancy. Surgery 130:971-977

37. Wells SA, Asa SL, Dralle H, Elisei R, Evans DB, Gagel RF et al (2015) Revised American Thyroid Association guidelines for the management of medullary thyroid carcinoma. Thyroid 25:567-610

38. Powell C (2003) The Delphi technique: myths and realities. J Adv Nurs 41:376-382

Publisher's Note Springer Nature remains neutral with regard to jurisdictional claims in published maps and institutional affiliations. 


\section{Authors and Affiliations}

Orhan Agcaoglu ${ }^{1} \cdot$ Atakan Sezer $^{2}(1) \cdot$ Ozer Makay $^{3} \cdot$ Murat Faik Erdogan $^{4} \cdot$ Fahri Bayram $^{5} \cdot$ Sibel Guldiken $^{6} \cdot$ Marco Raffaelli ${ }^{7}$. Yusuf Alper Sonmez ${ }^{8}$. Yong-Sang Lee ${ }^{9} \cdot$ Kyriakos Vamvakidis $^{10}$. Radu Mihai ${ }^{11}$. Quan-Yang Duh ${ }^{12}$. Baris Akinci ${ }^{13} \cdot$ Faruk Alagol $^{14}$ - Martin Almquist ${ }^{15} \cdot$ Marcin Barczynski $^{16} \cdot$ Taner Bayraktaroglu $^{17}$. Eren Berber $^{18}$. Yusuf Bukey ${ }^{19}$. Guldeniz Karadeniz Cakmak ${ }^{20}$. Nuh Zafer Canturk ${ }^{21}$. Zeynep Canturk ${ }^{22}$ - Mehmet Celik ${ }^{6}$. Ozlem Celik ${ }^{23}$. Banu Ozturk Ceyhan ${ }^{24}$. Sergii Cherenko ${ }^{25}$. Thomas Clerici ${ }^{26}$. David Scott Coombes ${ }^{27}$. Orhan Demircan ${ }^{28}$. Oguzhan Deyneli ${ }^{14}$. Gianlorenzo Dionigi ${ }^{29}$. Ali Ugur Emre ${ }^{20}$. Yesim Erbil ${ }^{24}$. Ali Ilker Filiz ${ }^{30}$. Hulya llıksu Gozu ${ }^{31}$. Sibel Ozkan Gurdal ${ }^{32}$. Gunay Gurleyik ${ }^{33}$. Mehmet Haciyanli ${ }^{34}$. Abut Kebudi ${ }^{30}$. Seokmo Kim ${ }^{9}$. Giannis Koutelidakis ${ }^{35}$. Bekir Kuru ${ }^{36}$. Meral Mert ${ }^{37}$. Guzide Gonca Oruk ${ }^{38}$. Serdar Ozbas ${ }^{24}$. Fausto Palazzo ${ }^{39}$. Rumen Pandev ${ }^{40}$. Phillip Riss ${ }^{41}$. Tevfik Sabuncu ${ }^{42}$. Ibrahim Sahin ${ }^{43}$. Gurhan Sakman ${ }^{44}$. Fusun Saygili ${ }^{45}$. Yasemin Giles Senyurek ${ }^{46}$. Ilya Sleptsov ${ }^{47}$. Sam Van Slycke ${ }^{48}$. Serkan Teksoz ${ }^{19} \cdot$ Tarik Terzioglu $^{49}$. Serdar Tezelman ${ }^{1} \cdot$ Fatih Tunca $^{46}$. Mustafa Umit Ugurlu ${ }^{50} \cdot$ Mehmet Uludag $^{51}$ - Jesus Villar-del-Moral ${ }^{52}$. Menno Vriens ${ }^{53} \cdot$ Dilek Yazici $^{14}$

1 Department of General Surgery, School of Medicine, Koc University, Istanbul, Turkey

2 Department of General Surgery, School of Medicine, Trakya University, Balkan Yerleskesi, 22030 Edirne, Turkey

3 Department of General Surgery, School of Medicine, Ege University, Bornova, Turkey

4 Department of Endocrinology and Metabolism, School of Medicine, Ankara University, Ankara, Turkey

5 Department of Endocrinology and Metabolism, School of Medicine, Erciyes University, Kayseri, Turkey

6 Department of Endocrinology and Metabolism, School of Medicine, Trakya University, Edirne, Turkey

7 Fondazione Policlinico Universitario Agostino Gemelli IRCCS, Università Cattolica del Sacro Cuore, Milan, Italy

8 Department of Endocrinology and Metabolism, Gulhane School of Medicine, University of Health Sciences, Istanbul, Turkey

9 Department of General Surgery, Gangnam Severance Thyroid Center, Yonsei University, Seoul, South Korea

10 Department of General Surgery, Henry Dunant Hospital Center, Athens, Greece

11 Department of General Surgery, Churchill Cancer Center, Oxford University, Oxford, UK

12 Department of General Surgery, University of California, San Francisco, USA

13 Department of Endocrinology and Metabolism, School of Medicine, Dokuz Eylul University, İzmir, Turkey

14 Department of Endocrinology and Metabolism, School of Medicine, Koc University, Istanbul, Turkey

15 Department of General Surgery, Skåne University Hospital, Malmö, Sweden

16 Department of General Surgery, Jagiellonian University Medical College, Kraków, Poland

17 Department of Endocrinology and Metabolism, School of Medicine, Zonguldak Bulent Ecevit University, Zonguldak, Turkey

18 Division of Endocrine Surgery, Department of General Surgery, Cleveland Clinic Foundation, Cleveland, USA
19 Department of General Surgery, School of Medicine, Cerrahpasa University, Istanbul, Turkey

20 Department of General Surgery, School of Medicine, Zonguldak Bulent Ecevit University, Zonguldak, Turkey

21 Department of General Surgery, School of Medicine, Kocaeli University, İzmit, Turkey

22 Department of Endocrinology and Metabolism, School of Medicine, Kocaeli University, İzmit, Turkey

23 Department of Endocrinology and Metabolism, School of Medicine, Acibadem University, Istanbul, Turkey

24 Private Practice, Istanbul, Turkey

25 Department of General Surgery, International Medical Center, Kyiv, Ukraine

26 Department of Endocrinology and Metabolism, Kantonsspital St. Gallen, St. Gallen, Switzerland

27 Department of General Surgery, University Hospital of Wales, Cardiff, Wales

28 Department of General Surgery, School of Medicine, Acibadem University, Istanbul, Turkey

29 Department of General Surgery, School of Medicine, Messina University, Messina, Italy

30 Department of General Surgery, School of Medicine, Okan University, Istanbul, Turkey

31 Department of Endocrinology and Metabolism, School of Medicine, Marmara University, Istanbul, Turkey

32 Department of General Surgery, Namik Kemal University, Zonguldak, Turkey

33 Department of General Surgery, Haydarpasa Numune Training and Research Hospital, Istanbul, Turkey

34 Department of General Surgery, İzmir Ataturk Training and Research Hospital, İzmir, Turkey

35 Department of General Surgery, Aristoteleio University of Thessaloniki, Thessaloniki, Greece

36 Department of General Surgery, School of Medicine, Ondokuz Mayis University, Samsun, Turkey

37 Department of Endocrinology and Metabolism, Bakirkoy Sadi Konuk Training and Research Hospital, İstanbul, Turkey 
38 Department of Endocrinology and Metabolism, Ataturk Training and Research Hospital, Katip Celebi University, İzmir, Turkey

39 Department of Endocrinology and Metabolism, Imperial College, Hammersmith Hospital, London, UK

40 Department of General Surgery, School of Medicine, Medical University Sofia, Sofia, Bulgaria

41 Department of General Surgery, School of Medicine, Medical University of Vienna, Vienna, Austria

42 Department of Endocrinology and Metabolism, School of Medicine, Harran University, Şanlıurfa, Turkey

43 Department of Endocrinology and Metabolism, School of Medicine, Malatya University, Malatya, Turkey

44 Department of General Surgery, School of Medicine, Cukurova University, Adana, Turkey

45 Department of Endocrinology and Metabolism, School of Medicine, Ege University, Bornova, Turkey
46 Department of General Surgery, Istanbul School of Medicine, Istanbul University, Istanbul, Turkey

47 North-West Center of Endocrinology and Metabolism, St. Petersburg State University, St. Petersburg, Russia

48 Department of General Surgery, Vattikutti Foundation, OLV Hospital, Aalst, Belgium

49 Department of General Surgery, VKV American Hospital, Istanbul, Turkey

50 Department of General Surgery, School of Medicine, Marmara University, Istanbul, Turkey

51 Department of General Surgery, Sisli Etfal Training and Research Hospital, Istanbul, Turkey

52 Department of General Surgery, Virgen De Las Nieves University Hospital, Granada, Spain

53 Department of General Surgery, University Medical Center Utrecht, Utrecht, Netherlands 